\title{
Silver and Zinc Oxide Nanoparticle Impregnated Jean Cloth Using Morinda Citrifolia (Noni) Fruits - Comparison of Antibacterial Activity
}

\author{
Sarvamangala $\mathrm{D}^{1}$, Kantipriya $\mathrm{K}^{2 *}$, Sivakumar $\mathrm{N}^{3}$ and Murthy $\mathrm{USN}^{4}$ \\ ${ }^{1}$ Associate professor, Department of Biotechnology, GIT, GITAM (Deemed to be \\ University), India \\ ${ }^{2}$ Research Scholar, Department of Biotechnology, GIT, GITAM (Deemed to be \\ University), India
}

\section{Research Article}

Volume 3 Issue 4

Received Date: September 01, 2018

Published Date: October 01, 2018

DOI: $10.23880 /$ nnoa- 16000150

3 Professor, Department of Biochemistry, School of Life Science, University of Hyderabad, India

${ }^{4}$ Professor, Department of Ophthalmology, Gayatri Vidya Parishad institute of health care and medical technology, Visakhapatnam, India

*Corresponding author: Kantipriya Kondala, Research Scholar, Department of Biotechnology, GIT, GITAM (Deemed to be University), Visakhapatnam-530045, India, Tel: 9989610082; Email: kantipriya.kondala@gmail.com

\section{Abstract}

Morinda citrifolia commonly called as Noni belongs to Rubiaceae family was used for synthesis of $\mathrm{Ag}$ and $\mathrm{ZnO}$ nanoparticles using Green synthesis method. Noni has unique medicinal properties which help in normalization of abnormally functioning cells by delivering the bio-chemical nutrients. Synthesized Ag and $\mathrm{ZnO}$ nanoparticles have been applied on to jean fabric by dip and cure method. Nanoparticles were characterized by different methods such as UVVISIBLE, FTIR, SEM, EDS, TEM and a comparative study of antimicrobial activity were done. Application of Ag and ZnO nanoparticles to jean fabric may reduce bacterial infections and blocks UV rays. Zone of inhibition of silver was almost similar to zinc oxide nanoparticles but comparative to silver, zinc oxide was cost effective and less toxic.

Keywords: Noni (Morinda citrifolia); Silver (Ag) and Zinc oxide (ZnO) nanoparticles; UV- VISIBLE; FTIR; SEM; EDS; TEM

Abbreviations: FTIR: Fourier Transform Infrared Spectroscopy; SEM: Scanning Electron Microscopy; EDS:
Energy Dispersive Spectroscopy; TEM: Transmission Electron Microscopy; SPR: Surface Plasmon Resonance; 


\section{Nanomedicine \& Nanotechnology Open Access}

\section{Introduction}

Morinda citrifolia (Noni) is also known as Indian Mulberry which is green small tree bearing flowers and fruits throughout the year. Noni plant contains several vitamins, minerals, and micro and macro nutrients and also provides with chemicals like proxeronine, xeronine, scopolitin, anthraquinones, damnacanthal which helps the body in various ways from cellular to organ level [1].

Morinda citrifolia (Noni) fruit juice is an alternative medicine for several diseases such as arthritis, diabetics, high blood pressure, muscle aches and pains, menstrual problems, headaches, heart diseases, AIDS, cancer, gastric ulcers, sprains, mental depression, senility, poor digestion, atherosclerosis, blood vessel problems and drug addiction [2,3]. Several pharmacological functions have been reported from fresh fruit extracts of noni such as analgesic [4], anti - inflammatory [5], antioxidant [6,7], immunomodulatory [8], anti - tumour [9], hepatoprotective [10], lowering of blood pressure and vasodilatory [11,12], cardio protective [13], antifungal [14], phyto estrogenic [15], wound healing [16], insulinotrophic [17] and anti - osteoporotic activity [18]. Few reports have been reported on the use of noni for CNS disorders such as anxiolytic and sedative [19], nontropic [20], antiepileptic [21], neuroprotective effect against stress - induced cognitive impairment [22] and some neuropharmacological effects [23].

Nanotechnology is a branch concerned with synthesis of nanoparticles of various sizes, shapes and compositions which involves in several applications. Green synthesis of nanoparticles is one of the ways of production of various metal and metal oxide nanoparticles such as cost effective and eco-friendly.

Now a day's most of the men and women are using jean pants and trousers and it is quite difficult to wash these clothes every day or after every use. If they are coated with silver and zinc oxide nanoparticles, they may be free of bacteria because both $\mathrm{Ag}$ and $\mathrm{ZnO}$ nanoparticles have tremendous antibacterial activity and also used for medical applications like wound dressing etc. Hence in the present study the production of $\mathrm{Ag}$ and $\mathrm{ZnO}$ nanoparticles using noni extract and comparison of their antibacterial study of nanoparticle coated jean fabric using dip, dry and cure method was observed.

\section{Materials and Methods}

\section{Materials}

Noni fresh fruits obtained from the trees present in the campus of GITAM (Deemed to be University),
Visakhapatnam, Silver nitrate $\left(\mathrm{AgNO}_{3}\right)$ was purchased from Hi Media laboratories Pvt Limited, Mumbai, India. Zinc sulphate $\left(\mathrm{ZnSO}_{4}\right)$ was purchased from Thermo Fisher Scientific India Pvt Limited, Delhi, India. Jean fabric.

\section{Methods}

\section{Preparation of Plant Extract}

Fresh fruits were washed, chopped with in to small pieces, known amount of fruit pulp (100 gm) was taken and ground with $100 \mathrm{ml}$ of distilled water and the filtrate was stored for further purpose [24].

\section{Preparation of $1 \mathrm{M}$ Silver nitrate $1 \mathrm{M} \mathrm{AgNO}_{3}$ solution}

$1 \mathrm{M}$ concentration of $\mathrm{AgNO}_{3}$ solution was prepared by dissolving $169 \mathrm{gms}$ of $\mathrm{AgNO}_{3}$ in $1000 \mathrm{ml}$ of distilled water and stored in amber coloured bottle to avoid oxidation of silver.

\section{Synthesis of Silver Nanoparticles (Procedure I)}

Synthesis of silver nanoparticles was done using $10 \mathrm{ml}$ of noni fruit extract was added with $90 \mathrm{ml}$ of $1 \mathrm{M}$ silver nitrate $\left(\mathrm{AgNO}_{3}\right)$ aqueous solution.

\section{Synthesis of Zinc Oxide Nanoparticles (Procedure II)}

Synthesis of Zinc oxide nanoparticles was done using $30 \mathrm{ml}$ of noni fruit extract was added with $70 \mathrm{ml}$ of $1 \mathrm{M}$ Zinc sulphate $\left(\mathrm{ZnSo}_{4}\right)$ aqueous solution.

\section{Characterization of Nanoparticles}

Silver nanoparticles and Zinc oxide nanoparticles were characterized by the following methods.

a) Visual observation: Aqueous fruit extract of Noni was mixed with $1 \mathrm{M}$ silver nitrate and zinc oxide solution and kept aside (in dark for silver for 4 hours and exposed to sunlight for 6 hours or heating at $60^{\circ} \mathrm{c}$ for 30 minutes) for observing colour change.

b) UV-Visible Spectroscopy (UV-VIS): The formation of Ag and $\mathrm{ZnO}$ nanoparticles were confirmed by spectral analysis using UV-Visible spectrophotometer SHIMADJU - 1800.

c) Fourier Transform Infrared Spectroscopy (FTIR): FTIR was used to know the biological components present in the nanoparticles and components involved in the nanoparticle formation. FTIR spectroscopy used for analysis was FTIR BRUKER by KBr pelleting method.

d) Scanning Electron Microscopy (SEM): To know morphology of the formed nanoparticles JSM-6610 SEM instrument equipped with a Thermo EDS attachment was done. A small amount of Ag and $\mathrm{ZnO}$ nanoparticles fine powder sample was coated on SEM grid and examined [24]. 


\section{Nanomedicine \& Nanotechnology Open Access}

e) Energy Dispersive Spectroscopy (EDS): To know the presence of elemental composition such as $\mathrm{Ag}$ and $\mathrm{Zn}$ were tested using EDS analysis.

f) Transmission Electron Microscopy (TEM): TEM analysis was done using TEM instrument JEOL 1200 EX operating at $120 \mathrm{kv}$ voltage. Thin film of the sample were prepared on a carbon coated grid by dropping a very small amount of the sample on the grid, extra solution was removed using a blotting paper. Later on, film on the TEM grid was allowed to dry by placing it under a mercury lamp for 5 minutes for the characterization of size and shape of synthesized silver nanoparticles [25].

g) Antibacterial activity: Antibacterial activity of the synthesized silver and zinc oxide nanoparticles was checked, using the agar well diffusion assay method [25]. Muller Hinton agar was poured in to sterilized Petri plates and bacterial test organisms were grown. 6 $\mathrm{mm}$ diameter of agar wells (well size equal to size of the fabric) was prepared. Then coated fabrics were inserted in to wells along with control and incubated at $37^{\circ} \mathrm{C}$ for $24-48$ hours. A clear zone of inhibition was observed and measurements were recorded later [26].

\section{Coating of Nanoparticles on to Jean Fabric}

The fabric was sterilized and dried in the hot air oven at $60^{\circ} \mathrm{C}$ for $5 \mathrm{~min}$. Dried jean fabric was immersed in $0.5 \%$ acrylic binder for $2 \mathrm{~min}$. and dried again for 1 minute. Measured and seizure piece of jean fabrics were dipped in to $0.5 \mathrm{ml}$ of $1 \mathrm{M} \mathrm{Ag}$ and $\mathrm{ZnO}$ nanoparticles for 20 minutes and air dried for 15 minutes and then cured at $100^{\circ} \mathrm{C}$ for 5 minutes. Such coated fabrics were subjected for antibacterial activity.

\section{Results and Discussion}

The results and interpretations of the characterization of synthesized $\mathrm{Ag}$ and $\mathrm{ZnO}$ nanoparticles have been discussed here such as UV, FTIR, FESEM, and EDAX.

Visual Observation: A colour change from pale yellow to reddish brown was observed in silver nanoparticles and light brown colour in zinc oxide nanoparticles. Colour change in silver nanoparticles is based on Surface Plasmon Resonance (SPR) [27].

UV-VISIBLE Spectroscopy: UV-VISIBLE absorption spectra shows that the maximum peak at $426 \mathrm{~nm}$ for silver nanoparticles and $360 \mathrm{~nm}$ for zinc oxide nanoparticles.

FTIR Analysis: (Figures $1 \& 2$ ) shows various peaks of conformation different bonds at their frequency range as follows. FTIR of Ag nanoparticles have shown a peak at 3421.47 which may represent $\mathrm{O}-\mathrm{H}$ group stretching and deformation, where peaks at 1631.41 and 690.75 correspond to Ag-O stretching and deformation [28]. FTIR of $\mathrm{ZnO}$ nanoparticles have shown a peak at 3447.95 may be $\mathrm{O}-\mathrm{H}$ stretching mode of hydroxyl group and peaks at 1557.51 and 1332.93 were due to asymmetrical and symmetrical stretching of the zinc carboxylate [29-31].

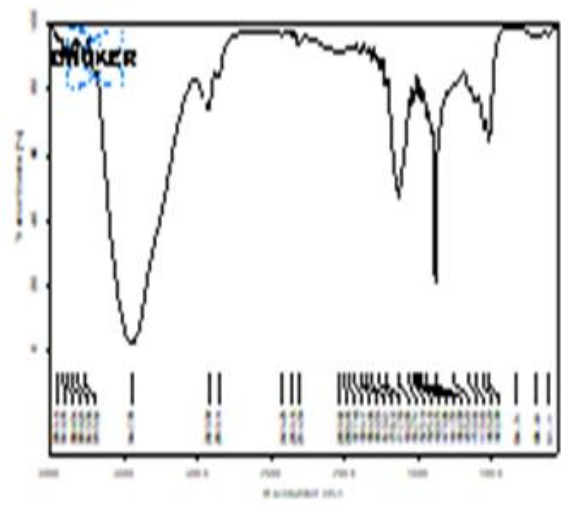

Ag nanoparticles

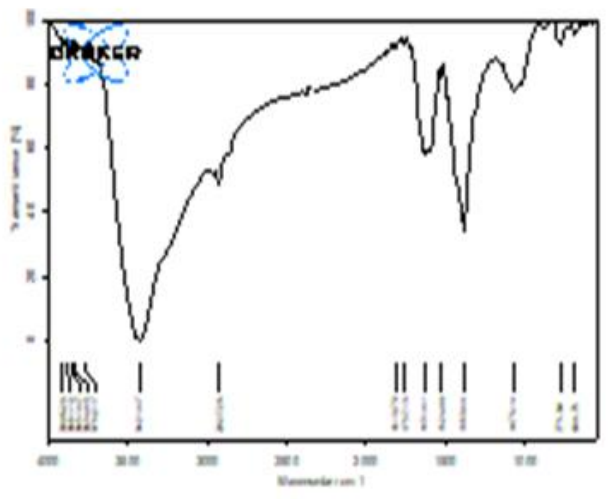

ZnO nanoparticles

Figures 1 \& 2: FTIR Analysis.

SEM Analysis and EDAX: In Figures 3 \& 4 SEM photo shows the morphology of nanoparticles as spherical and
EDAX photographs represents the elemental compounds presence (Ag and $\mathrm{Zn}$ ) in the Figure 5. 


\section{Nanomedicine \& Nanotechnology Open Access}

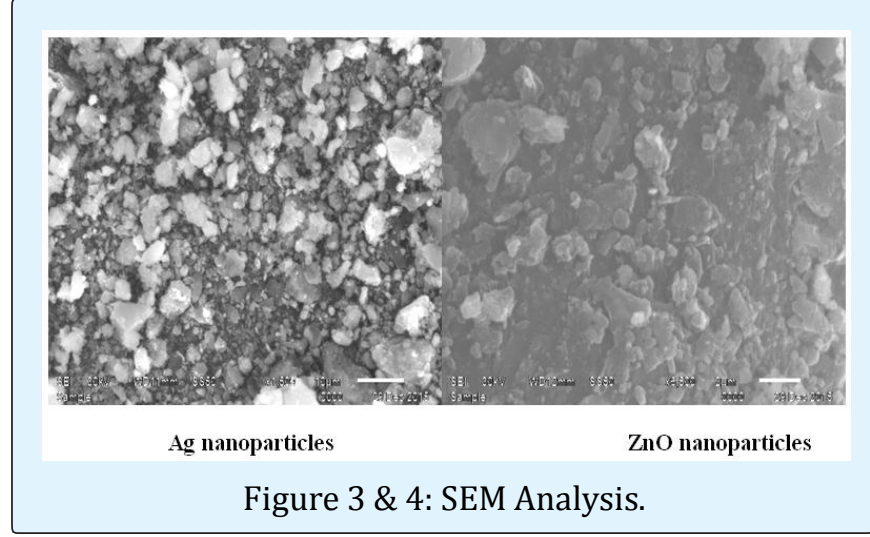

Project $1-$ Noni silver nanoparticles

Quantitative results
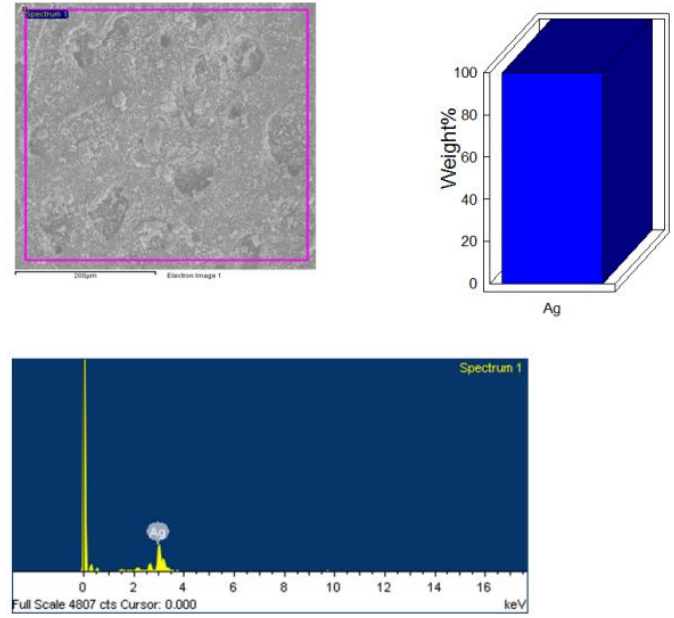

Project 2 - Noni zinc oxide nanoparticles

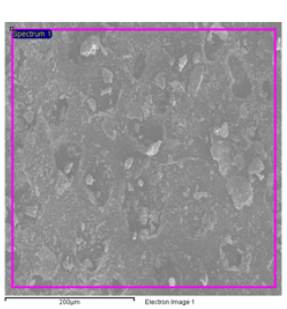

Quantitative results
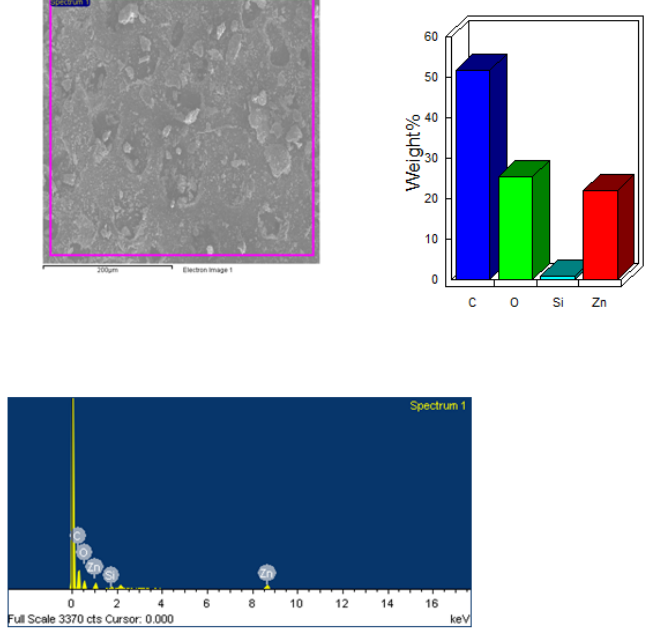

Figure 5: EDS Analysis of Ag \& ZnO nanoparticles
TEM Analysis: The size and shape of the nanoparticles were determined through this analysis Figure 6.

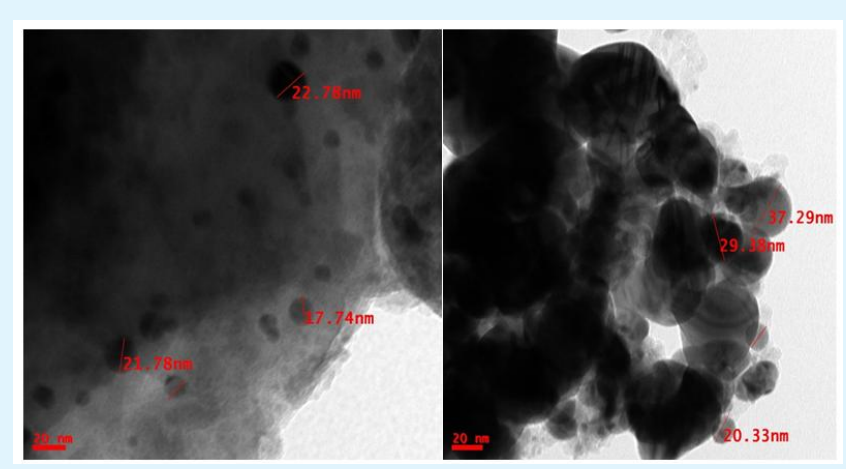

Figure 6: TEM Analysis.

Antibacterial Activity: Silver and Zinc Oxide nanoparticles exhibited good antibacterial properties against bacterial pathogens such as Staphylococcus aureus with 34 and $30 \mathrm{~mm}$ zone of inhibition, Streptococcus aeruginosa with 31 and $28 \mathrm{~mm}$ zone of inhibition and Pseudomonas aeruginosa with 28 and $26 \mathrm{~mm}$ zone of inhibition (Figures 7-10).

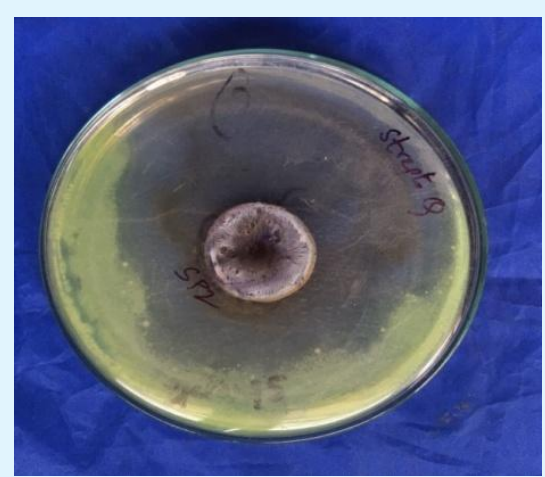

Figure 7: Streptococcusdisc inserted with Ag nanoparticle coated jean cloth.

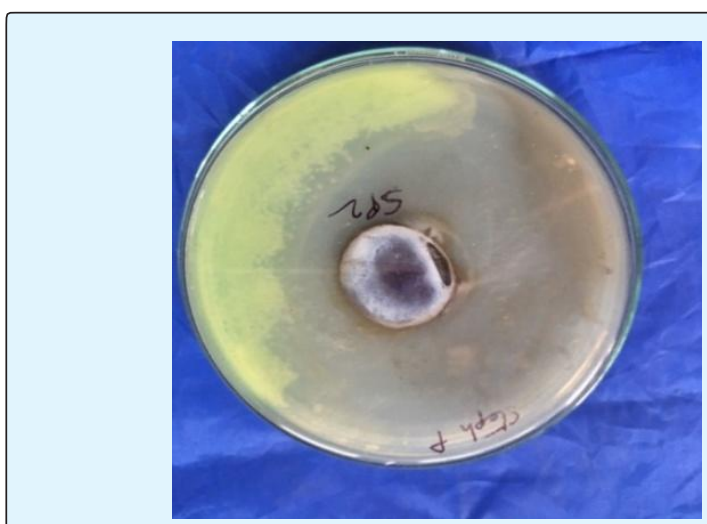

Figure 8: Staphylo coccusdisc inserted with $\mathrm{ZnO}$ nanoparticle coated jean cloth. 


\section{Nanomedicine \& Nanotechnology Open Access}

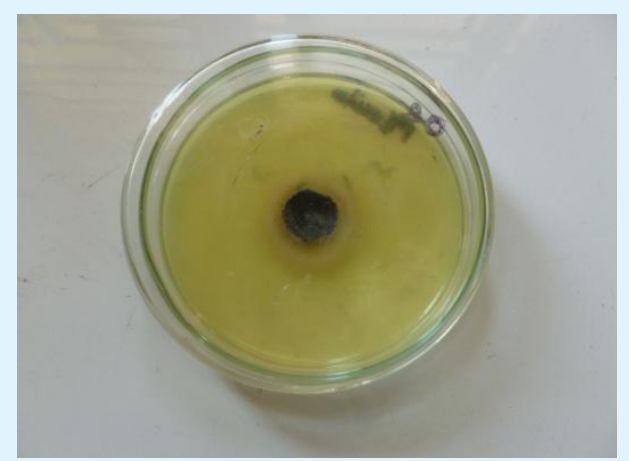

Figure 9: Pseudomonas aeruginosa disc inserted with ZnO nanoparticle coated jean cloth.

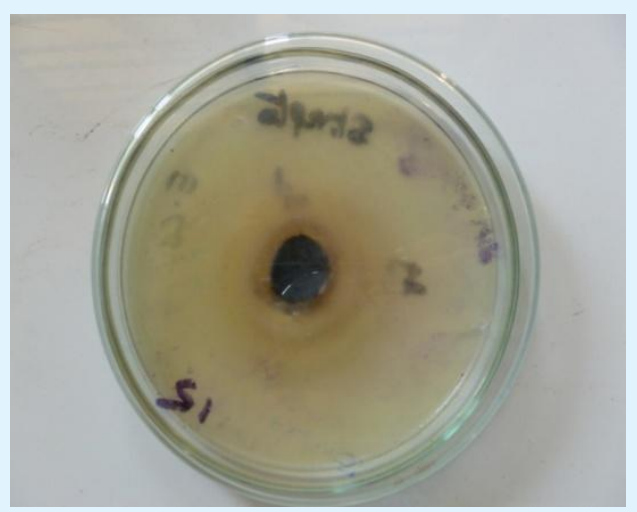

Figure 10: Strepto coccus disc inserted with silver nanoparticle coated jean cloth.

\section{Conclusion}

Green, eco-friendly and rapid formation of $\mathrm{Ag}$ and $\mathrm{ZnO}$ nanoparticles were synthesized by Morinda citrifolia (Noni) fruit extract and characterization have been performed. The development of colour change in the nanoparticles was confirmed by UV - Spectroscopy. Identification of functional groups in fruit which was responsible for reduction of nanoparticles was observed by FTIR analysis. Size and morphology of the nanoparticles were observed by SEM \& TEM. Presence of elemental silver and zinc were confirmed by EDS. The silver and zinc oxide nanoparticles synthesized using Noni fruit extract exhibited great inhibition against bacterial pathogens. It is observed that zinc oxide nanoparticles possess good antibacterial activity almost similar to silver nanoparticles and $\mathrm{ZnO}$ nanoparticles was cost effective and more environmental friendly when comparative to Ag nanoparticles. Present trend of men and women was usage of jeans for their convenience. Maintenance (washing and cleaning) of jean pants and trousers were very difficult and so the possible benefits and advantages of this application:

- About nanoparticle preparation - easy to handle, fast reaction, less time consuming, simple conversion, less toxic and low cost.

- Application - coating of nanoparticles on to jean fabric may reduce bacterial and fungal infections such as rash, irritation, reddishness of skin and allergic conditions etc.

Blocks UV rays and so it may act as anti UV. Avoids sun burns and also possess self-cleaning activity.

\section{References}

1. Rudra MP, Jahnavi A, Manisha DR, Vasanth KM, Sreedhar B, al. (2014) Interpretative in vitro phytochemical, TLC, synthesis of silver nanoparticles and their antibacterial screening of aqueous and ethanoic extracts of Morinda citrifolia L. (NONI) fruit and their comparative study. World journal of pharmaceutical research 3(6): 989-1007.

2. Wang MY, West BJ, Jensen CJ, Nowicki D, Su C, et al. (2002) Morinda citrifolia (Noni): a literature review and recent advances in Noni research. Acta Pharmacol Sin 23(12): 1127-1141.

3. Smita N, Rajani S (2010) Morinda citrifolia: a review. J Pharm Res 3(8): 1872-1874.

4. Younos C, Rolland A, Fleurentin J, Lanhers MC, Misslin $\mathrm{R}$, et al. (1990) Analgesic and behavioural effects of Morinda citrifolia. Planta Med 56(5): 430-434.

5. Pandy V, Narasingam M, Mohamed Z (2012) Antipsychotic-like activity of Noni (Morinda citrifolia Linn.) in mice. BMC Complementary and Alternative Medicine 12: 186.

6. Basar S, Uhlenhut K, Hogger P, Schone F, Westendorf J (2010) Analgesic and anti-inflammatory activity of Morinda citrifolia L. (Noni) fruit. Phytother Res 24(1): 38-42.

7. Su BN, Pawlus AD, Jung HA, Keller WJ, McLaughlin JL, et al. (2005) Chemical constituents of the fruits of Morinda citrifolia (Noni) and their antioxidant activity. J Nat Prod 68(4): 592-595.

8. Chanda S, Dave R, Kaneria M (2011) In vitro antioxidant property of some Indian medicinal plants. Res J Med Plant 5(2): 169-179.

9. Palu AK, Kim AH, West BJ, Deng S, Jensen J, et al. (2008) The effects of Morinda citrifolia L (noni) on 


\section{Nanomedicine \& Nanotechnology Open Access}

the immune system: its molecular mechanisms of action. J Ethnopharmacol 115(3): 502-506.

10. Hirazumi A, Furusawa E (1999) An immunomodulatory polysaccharide-rich substance from the fruit juice of Morinda citrifolia (noni) with antitumor activity. Phytother Res 13(5): 380-387.

11. Wang MY, Anderson G, Nowicki D, Jensen J (2008) Hepatic protection by noni fruit juice against CCl (4)induced chronic liver damage in female SD rats. Plant Foods Hum Nutr 63(3): 141-145.

12. Runnie I, Salleh MN, Mohamed S, Head RJ, Abeywardena MY (2004) Vasorelaxation induced by common edible tropical plant extracts in isolated rat aorta and mesenteric vascular bed. J Ethnopharmacol 92(2-3): 311-316.

13. Gilani AH, Mandukhail SR, Iqbal J, Yasinzai M, Aziz N, et al. (2010) Antispasmodic and vasodilator activities of Morinda citrifolia root extract are mediated through blockade of voltage dependent calcium channels. BMC Compl Altern Med 10: 2.

14. Salleh MN, Runnie I, Roach PD, Mohamed S, Abeywardena MY (2002) Inhibition of low-density lipoprotein oxidation and up-regulation of lowdensity lipoprotein receptor in HepG2 cells by tropical plant extracts. J Agric Food Chem 50(13): 3693-3697.

15. Banerjee S, Johnson AD, Csiszar K, Wansley $\mathrm{DL}$, McGeady P (2006) An extract of Morinda citrifolia interferes with the serum-induced formation of filamentous structures in Candida albicans and inhibits germination of Aspergillus nidulans. Am J Chin Med 34(3): 503-509.

16. Chearskul S, Kooptiwut S, Chatchawalvanit S, Onreabroi S, Churintrapun M, et al. (2004) Morinda citrifolia has very weak estrogenic activity in vivo. Thai J Physiol Sci 17(1): 22-29.

17. Palu A, Su C, Zhou BN, West B, Jensen J (2010) Wound healing effects of noni (Morinda citrifolia L.) leaves: a mechanism involving its PDGF/A2A receptor ligand binding and promotion of wound closure. Phytother Res 24(10): 1437-1441.

18. Hamid M, Bohari SPM, Bastami MS, Ali AM, Mustapha $\mathrm{NM}$, et al. (2008) Evaluation of the insulinotrophic activity of Malaysian traditional plants extract. J Biol Sci 8: 201-204.
19. Shirwaikar A, Kamariya Y, Patel B, Nanda S, Parmar V, et al. (2011) Methanol extract of the fruits of Morinda citrifolia Linn. Restores bone loss in ovariectomized rats. Int J Pharmacol 7(4): 446-454.

20. Deng S, West BJ, Palu AK, Zhou BN, Jensen CJ (2007) Noni as an anxiolytic and sedative: a mechanism involving its gamma-aminobutyric acidergic effects. Phytomed 14(7-8): 517-522.

21. Muralidharan P, Kumar VR, Balamurugan G (2010) Protective effect of Morinda citrifolia fruits on betaamyloid (25-35) induced cognitive dysfunction in mice: an experimental and biochemical study. Phytother Res 24(2): 252-258.

22. Muralidharan P, Srikanth J (2010) Anti-Epileptic activity of Morinda citrifolia Linn fruit extract. E- J Chem 7(2): 612-616.

23. Muto J, Hosung L, Uwaya K, Isami F, Ohno M, et al. (2010) Morinda citrifolia fruit reduces stress-induced impairment of cognitive function accompanied by vasculature improvement in mice. Physiol Behav 101(2): 211-217.

24. Margarita BU, Sanchez N, Perez-Saad H, Gloria L, Isidoro S (2011) Perfil neuropharmacological del zumo de Morinda citrifolia. Bol Latinoam Caribe Plant. Med Aromat 10(2): 159-166.

25. Sarvamangala D, Kantipriya K, Geetha S, Manga S (2017) Nanoparticle coated bandage cloth Antimicrobial activity. European Journal of Biomedicaland Pharmaceutical Sciences 4(11): 510513.

26. Sarvamangala D, Kantipriya K, Murthy USN, Narasinga RB, Sivakumar N (2014) Green Synthesis of AgNP'S Using Alternanthera Sessilis Leaf Extract [A Natural Source for Ocular Therapy]. International Journal of Innovative Research in Science, Engineering and Technology 3(7): 15000-15010.

27. Huang HL, Ko CH, Yeong-Yu Y, Chin Kun W (2014) Antiadhesion and Anti-inflammation Effects of Noni (Morinda citrifolia) Fruit Extracts on AGS Cells during Helicobacter pylori Infection. J Agric Food Chem 62(11): 2374-2383.

28. Perez C, Paul M, Bazerque P (1990) Antiinflammation Effects of Noni (Morinda citrifolia). Acta Biol Med Exp 15: 113. 


\section{Nanomedicine \& Nanotechnology Open Access}

29. Prathna TC, Ashok MR, Chandrasekaran N, Amitava M (2014) Sunlight Irradiation Induced Green Synthesis of Stable Silver Nanoparticles Using Citrus Limon Extract. Proceedings of the National Academy of Sciences, India Section B: Biological Sciences 84(1): 65-70.

30. Harish K, Renurani (2013) Structural characterization of silver nanoparticles synthesized by micro emulsion route. International journal of engineering and innovative technology 3(3): 344-348.

31. Xiong G, Pal U, Serrano JG, Ucer KB, Williams RT (2006) Photoluminescence and FTIR study of ZnO nanoparticles: the impurity and defect perspective. Physical Status Solidi C 3(10): 3577-3581. 